\title{
Prevalence and risk factors of gestational diabetes mellitus among pregnant patients visiting National Guard primary health care centers in Saudi Arabia
}

Saleem A. Alsaedi, MBBS, Abdullah A. Altalhi, MBBS, Mutaz F. Nabrawi, MBBS, Abdulrahman A. Aldainy, MBBS,

Razaz M. Wali, MBBS, SBFM.

\begin{abstract}
الهدف : نحن نهاف إلى تقييم مدى انتشار وعوامل الخطر لمرض سكري الحمل

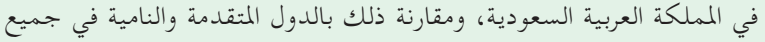
أنحاء العالم.

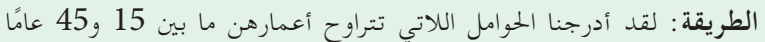

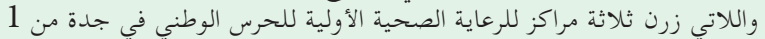

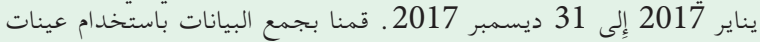

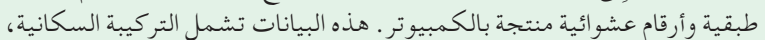

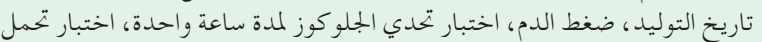

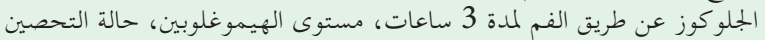

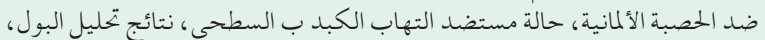

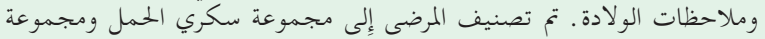

بدون سكري الحمل اعتمادا على اختباري تحدي الجلميلو كوز وتحمل الجلوكوز

النتائج : في المجموع، تم تسجيل 347 امرأة في الدراسة (متوسط العمر، 28.79 المباس

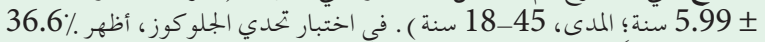

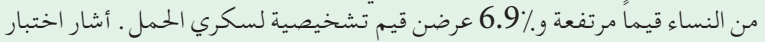

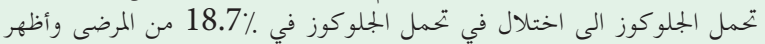

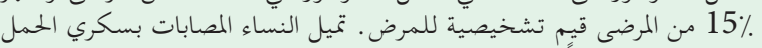
لأن يكونن أكبر سناً ولد يهن قيم أكبر في مؤشر كتلة الجسم.

الحلاصة: إن انتشار سكري الحمل في المملكة العربية السعودية مرتفع مقارنة

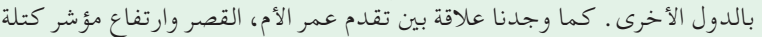

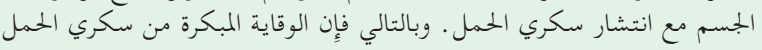

$$
\text { ومعالجته أمر ضروري لتقليل المخاطر على كل من الأم والجنين. }
$$
\end{abstract}

Objectives: To measure the prevalence of gestational diabetes mellitus (GDM) and its risk factors in Saudi Arabia, in comparison with developed and developing countries worldwide.

Methods: We enrolled pregnant women aged 15-45 years who visited 3 National Guard-Health Affairs' primary health care centers in Jeddah, Saudi Arabia between January 2017 and December 2017. We used stratified samples and computer-generated random numbers to collect data. This data includes demographics, obstetric history, blood pressure, non-fasting 1-hour glucose challenge test (GCT), 3-hour oral glucose tolerance test (OGTT), hemoglobin level, rubella immunization status, hepatitis B surface antigen status, urinalysis results, and labor, and delivery notes. We categorized the patients into 2 groups, GDM and non-GDM, based on GCT and OGTT.

Results: We enrolled 347 women in the study (mean age, $28.8 \pm 6$ years; range, $18-45$ years). On GCT, $36.6 \%$ of women showed abnormal values and $6.9 \%$ exhibited diagnostic values. Oral glucose tolerance test indicated impairment in $18.7 \%$ of patients and a diagnostic finding in $15 \%$ of patients. Women diagnosed with GDM tended to be older and have greater body mass index (BMI) values.

Conclusion: The prevalence of GDM in Saudi Arabia is high compared to other countries. Advanced maternal age and higher BMI values were associated with increased prevalence of GDM. Thus, early prevention and management of GDM is vital to minimize the risks to both the mother and fetus.

Keywords: gestational diabetes mellitus, primary care, BMI, pregnancy, glucose tolerance

Saudi Med J 2020; Vol. 41 (2): 144-150

doi: 10.15537/smj.2020.2.24842

From the College of Medicine (Alsaedi, Altalhi, Nabrawi, Aldainy, Wali), King Saud bin Abdulaziz University for Health Sciences, from King Abdullah International Medical Research Center (Alsaedi, Altalhi, Nabrawi, Aldainy, Wali), and from the Ministry of National Guard - Health Affairs (Alsaedi, Altalhi, Nabrawi, Aldainy, Wali), Jeddah, Kingdom of Saudi Arabia.

Received 4th August 2019. Accepted 4th December 2019.

Address correspondence and reprint request to: Dr. Saleem A. Alsaedi, College of Medicine, King Saud bin Abdulaziz University for Health Sciences, Jeddah, Kingdom of Saudi Arabia. E-mail: saleem1416.ios@gmail.com

ORCID ID: https://orcid.org/0000-0001-6152-9205 
T he American Diabetes Association (ADA) defines gestational diabetes mellitus (GDM) as diabetes diagnosed in the second or third trimester of pregnancy that was not clearly overt diabetes prior to gestation. ${ }^{1}$ There are many risk factors for GDM including history of unexplained stillbirth, history of delivering a macrosomic fetus (defined as birth weight $>90$ th percentile), obesity, age $>25$ years, congenital malformations, and a strong family history of type 2 diabetes. ${ }^{2,3}$ Ethnicity play a role in the contribution of each risk factor, as they vary in their prevalence among different populations. ${ }^{4}$ Gestational diabetes mellitus affects both the mother and the fetus, and thus it is vital to detect such condition promptly. The effects on the mother include mild or severe preeclampsia, eclampsia, higher likelihood of preterm delivery, induction of labor, cesarean section, intrauterine fetal demise, and infant death. ${ }^{5}$ Furthermore, up to $50 \%$ of patients with GDM are at a risk of developing type 2 diabetes mellitus. ${ }^{6}$ The effects of GDM on the child can be classified into: fetal and neonatal defects (including macrosomia, delayed organ maturity, hypocalcemia, and hypoglycemia); and fetal compromise (including intrauterine growth restriction and fetal death). ${ }^{2}$ Early identification of GDM and appropriate management are vital to prevent these complications. Patients usually undergo screening for GDM between the 24th to 28th gestational week, unless the patient is at high risk of developing GDM; in those cases, screening is conducted at the first antenatal visit. ${ }^{7}$ Early GDM treatment is associated with better pregnancy outcomes and has been found to be costeffective. ${ }^{8}$ Gestational diabetes mellitus screening can be conducted using tests such as the non-fasting $50 \mathrm{~g}$ 1-hour glucose challenge test (1-h GCT), $100 \mathrm{~g} \mathrm{3-h}$ oral glucose tolerance test (3-h OGTT), and $75 \mathrm{~g} 2-\mathrm{h}$ oral glucose tolerance test (2-h OGTT). The ADA recommends using either a one-step approach with the 2-h OGTT or a 2-step approach involving screening with the 1-h GCT, tailed by the 3-h OGTT for those testing positive for 1-h GCT. ${ }^{1,9}$ The aim of this study is to measure the prevalence of GDM and its risk factors among pregnant patients in Saudi Arabia, in comparison with those in developed and developing countries worldwide

Methods. In this record-based observational analytical retrospective cohort study, we enrolled

Disclosure. Authors have no conflict of interests, and the work was not supported or funded by any drug company. patients visiting National Guard (NGHA) Primary Health Care Centers in Jeddah, Saudi Arabia, between January 2017 and December 2017. There are 3 primary health care centers with antenatal clinics that continuously follow-up pregnant women in Jeddah, including the Al-Waha specialized polyclinics, King Faisal Residential City Centers (Jeddah Housing), and Bahrah centers.

In 2017, 2040 pregnant females visited the 3 clinics. Using Raosoft ${ }^{\oplus}$ software, with a confidence interval (CI) of $95 \%$ and a margin of error of $\pm 5 \%$, we estimated that the ideal sample size would be 347 . We used the stratified random sampling technique with computergenerated random numbers. Patients were stratified by the primary health care centers. Al-Waha specialized polyclinics accounted for $66 \%$ of the population, and $66 \%$ of the sample was taken from there. The same rule applies to King Faisal Residential City (Jeddah Housing) which accounted for $12 \%$ and Bahrah centers for $22 \%$.

We enrolled pregnant women aged 15-45 years who visited the centers during the study period, and excluded those who were already diagnosed with diabetes mellitus type 1 or 2 , and patients without complete 1-h GCT data. After obtaining patient medical record numbers (MRN), we used BESTCare software to access patients' electronic files and antenatal follow-up sheets, investigation panel information, and labor and delivery notes. After obtaining approval from the Institutional Review Board, data were collected from the patients' electronic files. The data included demographics, obstetric history, systolic and diastolic blood pressure, 1-h GCT, 3-h OGTT, hemoglobin level, rubella immunization status, hepatitis B surface antigen status, urinalysis results, and labor and delivery notes. The demographic data included age, height, and weight. Obstetric history included gravidity, parity, occurrence of previous abortions, or prior macrosomic fetus delivery. The gestational age at delivery, mode of delivery, gender of the baby, and birth weight were obtained from the labor and delivery notes.

According to the ADA, the 2-step method of GDM diagnosis requires screening at 24-28 weeks of gestation. The first step involves the 1-h GCT, which can indicate diagnostic or positive findings, and is tailed by a confirmation test with the 3-h OGTT, which can indicate either impaired glucose tolerance or the presence of GDM. If the pregnant woman exhibits risk factors for GDM, screening is usually performed during the first antenatal visit.

Statistical analysis. The statistical analysis was performed by the Statistical Package for Social Sciences 
for Windows, version 24.0 (IBM Corp, Armonk, NY, USA). For descriptive statistics, we used percentage and frequency for qualitative variables. For quantitative variables, firstly, we determined the distribution through visual review of histograms, normal Q-Q plots, and box plots, in addition to Shapiro-Wilk test. Secondly, we used mean and standard deviation for normally distributed quantitative variables, and median and interquartile range for skewed quantitative variables. For inferential statistics, Pearson's Chi-squared method was used to test the relationship between GDM and the qualitative independent variables. Fisher-exact test was used to test the relationship between GDM and qualitative independent variables with small expected numbers. Depending on the distribution, either t-tests or Man-Whitney tests were used to test the relationship between GDM and the quantitative independent variables. A $p<0.05$ is considered statistically significant.

Results. A total of 347 women were included in this study, and their baseline characteristics are shown in Table 1. The prevalence of GDM was $19.6 \%(68 / 347)$ in the population. Regarding 1-h GCT findings, 36.6\% (127/347) of the enrolled women showed abnormal values and $6.9 \%(24 / 347)$ exhibited values diagnostic of GDM. Three-hour OGTT indicated glucose impairment in $12.5 \%(13 / 104)$ of the patients, and a diagnostic finding in 50\% (52/104) of patients.

Included patients had a mean age of $28.8 \pm 6$ years (range, $18-45$ years). Gestational diabetes mellitus group patients were significantly older, relative to the non-GDM group (mean age, $28.1 \pm 5.6$ versus [vs.] $31.7 \pm 6.6$ years; $\mathrm{t}(345):-4.6, p<0.001)$. Furthermore, $29.45 \%(38 / 129)$ of women aged $>30$ years were diagnosed with GDM, which accounted for $55.9 \%$ of the entire GDM group. In comparison, only $11.1 \%$ $(2 / 18)$ of women aged 18 to 20 years were diagnosed with GDM; these values were significantly different $\left(\chi^{2}(3): 14.1, p=0.003\right)$ (Table 2).

Gestational diabetes mellitus group patients had a mean BMI of $29.3 \pm 6.2 \mathrm{~kg} / \mathrm{m}^{2}$ (range, $12.6-47.8 \mathrm{~kg} / \mathrm{m}^{2}$ ), Which is significantly higher compared to the non-GDM group (mean BMI, $30.6 \pm 6.1 \mathrm{~kg} / \mathrm{m}^{2}$ vs. $28.9 \pm 6.2 \mathrm{~kg} / \mathrm{m}^{2}$; $\mathrm{t}(340):-2.0 ; p=0.045)$. In addition, $27.1 \%(38 / 140)$ of obese women were diagnosed with GDM, which accounted for $55.9 \%$ of the entire GDM group. In comparison, $15.6 \%$ (14/90) of women with normal BMI were diagnosed with GDM; these values were found to be significantly different $(p=0.028)$ (Table 2$)$.

Even though $58.8 \%(40 / 68)$ of women diagnosed with GDM had blood group O, blood groups were not significantly associated with $\operatorname{GDM}\left(\chi^{2}(3): 1.35\right.$,
Table 1 - Baseline characteristics of patients ( $N=347)$.

\begin{tabular}{|c|c|}
\hline Characteristics & $\mathrm{n}(\%)$ \\
\hline Age $($ mean $\pm S D)$ & $28.8 \pm 6.0$ \\
\hline Body mass index $\left(\mathrm{kg} / \mathrm{m}^{2}\right)$ & $29.3 \pm 6.2$ \\
\hline \multicolumn{2}{|l|}{ Blood group } \\
\hline $\mathrm{O}$ & $211(60.8)$ \\
\hline A & $88(25.4)$ \\
\hline $\mathrm{B}$ & $42(12.1)$ \\
\hline $\mathrm{AB}$ & $6(1.7)$ \\
\hline Hemoglobin $(\mathrm{g} / \mathrm{dL})(\operatorname{mean} \pm \mathrm{SD})$ & $11.3 \pm 1.1$ \\
\hline Gravidity $^{\dagger}$ & $3(4.0)$ \\
\hline Parity $^{\dagger}$ & $1(2.0)$ \\
\hline Smoking & $8 \quad(2.3)$ \\
\hline \multicolumn{2}{|l|}{ Gestational age } \\
\hline Preterm ( $<37$ weeks $)$ & $19 \quad(5.5)$ \\
\hline Term & $309(89.0)$ \\
\hline Post-term (>42 weeks) & $2(0.6)$ \\
\hline Birth weight $(\mathrm{kg})($ mean $\pm S D)$ & $3.0 \pm 0.5$ \\
\hline \multicolumn{2}{|l|}{ Type of delivery } \\
\hline Vaginal delivery & $231(66.6)$ \\
\hline Cesarian section & $95(27.4)$ \\
\hline \multicolumn{2}{|l|}{ Glucose challenge test } \\
\hline Normal & $220(63.4)$ \\
\hline Elevated & $103(29.7)$ \\
\hline Diagnostic & $24(6.9)$ \\
\hline \multicolumn{2}{|l|}{ Glucose tolerance test } \\
\hline Negative & $39(11.2)$ \\
\hline Impaired & $13(3.7)$ \\
\hline Diagnostic & $52(15.0)$ \\
\hline Not performed & $243(70.0)$ \\
\hline \multicolumn{2}{|l|}{ Gestational diabetes mellitus } \\
\hline Yes & $\begin{array}{c}68(19.6) \\
(16.2-23.9)^{\ddagger}\end{array}$ \\
\hline No & $279(80.4)$ \\
\hline
\end{tabular}

Table 2 - Association between demographic variables and gestational diabetes mellitus ( $\mathrm{N}=347)$.

\begin{tabular}{|c|c|c|c|}
\hline Demographic data & $\begin{array}{l}\text { Non-GDM } \\
(\mathrm{n}=279)\end{array}$ & $\begin{array}{c}\text { GDM } \\
(n=68)\end{array}$ & $P$-value* \\
\hline Age $($ mean $\pm S D)$ & $28.1 \quad(5.6)$ & $31.7(6.6)$ & $<0.0001$ \\
\hline \multicolumn{4}{|l|}{ Age categories $^{\dagger}$} \\
\hline $18-20$ & $16 \quad(5.7)$ & $2(2.9)$ & 0.03 \\
\hline $21-25$ & $91(32.6)$ & $11(16.2)$ & \\
\hline $26-30$ & $81(29.0)$ & $17(25.0)$ & \\
\hline$>30$ & $91 \quad(32.6)$ & $38(55.9)$ & \\
\hline $\begin{array}{l}\text { Body mass index }{ }^{\ddagger} \\
(\text { mean } \pm S D)\end{array}$ & $28.9 \quad(6.1)$ & $\begin{array}{l}30.6 \\
(6.2)\end{array}$ & 0.045 \\
\hline \multicolumn{4}{|l|}{$\begin{array}{l}\text { Body mass index } \\
\text { categories }\end{array}$} \\
\hline Underweight, $<18.5$ & $5 \quad(1.8)$ & $1 \quad(1.5)$ & 0.028 \\
\hline Normal, 18.5-24.9 & $76 \quad(27.2)$ & $14(20.6)$ & \\
\hline Overweight, 25-29.9 & $93 \quad(33.3)$ & $14(20.6)$ & \\
\hline Obese, $\geq 30$ & $102(36.55)$ & $38(55.9)$ & \\
\hline
\end{tabular}


$p=0.715)$. Furthermore, parity, gravidity, history of smoking, previous macrosomic fetus delivery, and previous cesarian section were not associated with GDM in the present study. The gestational age of the born child, mode of delivery, and gender were also not associated with GDM (Tables $3 \& 4$ ).

Discussion. In 1828, the first description of GDM was made when a lady was diagnosed with diabetes during pregnancy, which resolved after delivery. ${ }^{10}$ The patient had signs and symptoms of severe hyperglycemia, and the delivered child was macrosomic and stillborn. Later in 1957, such cases were labeled as gestational diabetes. ${ }^{11}$

The International Diabetes Federation (IDF)

Table 3 - Association between obstetric and delivery variables and gestational diabetes mellitus $(\mathrm{N}=347)$.

\begin{tabular}{|c|c|c|c|}
\hline \multirow[t]{2}{*}{ Variables } & \multicolumn{2}{|c|}{ Frequency } & \multirow[t]{2}{*}{$P$-value* } \\
\hline & $\begin{array}{l}\text { Non-GDM } \\
(\mathrm{n}=279)\end{array}$ & $\begin{array}{l}\text { GDM } \\
(n=68)\end{array}$ & \\
\hline \multicolumn{4}{|l|}{ Obstetric history } \\
\hline Gravidity $\dagger$ & (3) & (5) & 0.189 \\
\hline Parity $\dagger$ & (2) & (4) & 0.231 \\
\hline \multicolumn{4}{|l|}{ Miscarriages } \\
\hline Yes & $85(30.5)$ & $23(33.8)$ & \multirow{2}{*}{0.592} \\
\hline No & $194(69.5)$ & $45(66.2)$ & \\
\hline \multicolumn{4}{|c|}{ Multiple gestations } \\
\hline Yes & $5 \quad(1.8)$ & $2 \quad(2.9)$ & \multirow{2}{*}{0.447} \\
\hline No & $273(97.8)$ & $66(97.1)$ & \\
\hline \multicolumn{4}{|c|}{ Previous macrosomia } \\
\hline Yes & $1 \quad(0.4)$ & $1 \quad(1.5)$ & \multirow{2}{*}{0.975} \\
\hline No & $278(99.6)$ & $67(98.5)$ & \\
\hline \multicolumn{4}{|c|}{$\begin{array}{l}\text { Previous caesarean } \\
\text { section }\end{array}$} \\
\hline Yes & $61(21.9)$ & $14(20.6)$ & \multirow{2}{*}{0.819} \\
\hline No & $218(78.1)$ & $54(79.4)$ & \\
\hline \multicolumn{4}{|c|}{ Blood pressure at initial visit } \\
\hline Elevated & $59(21.1)$ & $21(30.9)$ & \multirow{2}{*}{0.087} \\
\hline Normal & $220(78.9)$ & $47(69.1)$ & \\
\hline \multicolumn{4}{|l|}{ Delivery history } \\
\hline \multicolumn{4}{|l|}{ Gestational age } \\
\hline Preterm & $13(4.65)$ & $6 \quad(8.8)$ & \multirow{2}{*}{0.180} \\
\hline Term & $252(90.3)$ & $59(86.8)$ & \\
\hline \multicolumn{4}{|l|}{ Type of delivery } \\
\hline Vaginal & $188(67.4)$ & $43(63.2)$ & \multirow{2}{*}{0.471} \\
\hline Cesarian & $74(26.5)$ & $21(30.9)$ & \\
\hline \multicolumn{4}{|c|}{ Gender of the baby } \\
\hline Male & $145(52.0)$ & $38(55.9)$ & \multirow{2}{*}{0.792} \\
\hline Female & $119(42.7)$ & $29(42.6)$ & \\
\hline $\begin{array}{l}\text { Birth weight } \\
(\text { mean } \pm S D)\end{array}$ & $2.9 \pm 0.5$ & $3.0 \pm 0.3$ & 0.981 \\
\hline \multicolumn{4}{|c|}{$\begin{array}{l}{ }^{*} \text { T-test was used. Mann-Whitney test was used for gravidity and parity } \\
{ }^{\dagger} \text { Median and interquartile range are presented instead of frequency } \\
\text { and percentage, respectively. Values are presented as numbers and } \\
\text { percentages (\%). GDM: gestational diabetes mellitus }\end{array}$} \\
\hline
\end{tabular}

Table 4 - Association between medical and laboratory variables and gestational diabetes mellitus $(\mathrm{N}=347)$.

\begin{tabular}{|c|c|c|c|c|}
\hline \multirow[t]{2}{*}{ Variables } & \multicolumn{3}{|c|}{ Frequency } & \multirow[t]{2}{*}{$P$-value* } \\
\hline & \multicolumn{2}{|c|}{ Non-GDM $(\mathrm{n}=279)$} & $\operatorname{GDM}(n=68)$ & \\
\hline \multicolumn{5}{|l|}{ Medical history } \\
\hline \multicolumn{5}{|l|}{ Hypertension } \\
\hline Yes & 1 & $(0.35)$ & $\begin{array}{ll}0 & (0)\end{array}$ & 0.843 \\
\hline No & 277 & (99.3) & $68(100.0)$ & \\
\hline \multicolumn{5}{|c|}{ Thyroid diseases } \\
\hline Yes & 21 & $(7.5)$ & $7 \quad(10.3)$ & 0.452 \\
\hline No & 258 & $(92.5)$ & $61 \quad(89.7)$ & \\
\hline \multicolumn{5}{|c|}{ Cardiac diseases } \\
\hline Yes & 0 & (0) & $1 \quad(1.45)$ & 0.390 \\
\hline No & 277 & (99.3) & $67 \quad(98.5)$ & \\
\hline \multicolumn{5}{|c|}{ Neurological diseases } \\
\hline Yes & 1 & $(0.35)$ & $1 \quad(1.5)$ & 0.289 \\
\hline No & 278 & (99.6) & $67 \quad(98.5)$ & \\
\hline \multicolumn{5}{|l|}{ Renal diseases } \\
\hline Yes & 2 & $(0.7)$ & $1 \quad(1.5)$ & 0.404 \\
\hline No & 275 & (98.6) & $67 \quad(98.5)$ & \\
\hline \multicolumn{5}{|c|}{ Blood transfusion } \\
\hline Yes & 15 & (5.4) & $6 \quad(8.8)$ & 0.292 \\
\hline No & 262 & (93.9) & $62 \quad(91.2)$ & \\
\hline \multicolumn{5}{|l|}{ Allergy } \\
\hline Yes & 10 & (3.6) & $3 \quad(4.4)$ & 0.756 \\
\hline No & 267 & $(95.7)$ & 65 (95.6) & \\
\hline \multicolumn{5}{|l|}{ Infection } \\
\hline Yes & 3 & (1.1) & $0(0)$ & 0.603 \\
\hline No & 276 & $(98.9)$ & $67 \quad(98.5)$ & \\
\hline \multicolumn{5}{|l|}{ Smoking } \\
\hline Yes & 6 & $(2.15)$ & $2 \quad(2.9)$ & 0.401 \\
\hline No & 268 & $(96.1)$ & $65 \quad(95.6)$ & \\
\hline \multicolumn{5}{|l|}{ Consanguinity } \\
\hline Yes & 70 & $(25.1)$ & $24 \quad(35.3)$ & 0.080 \\
\hline No & 203 & $(72.8)$ & $42(61.8)$ & \\
\hline Laboratory tests & & & & \\
\hline Hemoglobin & $\mathrm{an} \pm \mathrm{SD}$ ) & & & \\
\hline Non-GDM & & $11.3=$ & & 0.840 \\
\hline GDM & & $11.3=$ & & \\
\hline Antibodies & & & & \\
\hline Positive & 4 & (1.4) & $1 \quad(1.5)$ & 0.995 \\
\hline Negative & 266 & $(95.3)$ & $66(97.05)$ & \\
\hline $\begin{array}{l}\text { Hepatitis B su } \\
\text { antigen (Hbs }\end{array}$ & & & & \\
\hline Positive & 0 & (0) & $1 \quad(1.5)$ & 0.151 \\
\hline Negative & 274 & $(98.2)$ & $65 \quad(95.6)$ & \\
\hline Proteinuria & & & & \\
\hline Positive & 27 & $(9.7)$ & $7(10.3)$ & 0.855 \\
\hline Negative & 247 & $(88.5)$ & $59(86.8)$ & \\
\hline Ketonuria & & & & \\
\hline Positive & 15 & $(5.4)$ & $6 \quad(8.8)$ & 0.284 \\
\hline Negative & 260 & $(93.2)$ & $61 \quad(89.7)$ & \\
\hline Glycosuria & & & & \\
\hline Positive & 2 & $(0.7)$ & $2 \quad(2.9)$ & 0.123 \\
\hline Negative & 273 & $(97.8)$ & $65 \quad(95.6)$ & \\
\hline Blood groups & & & & \\
\hline $\mathrm{O}$ & 171 & $(61.3)$ & $40 \quad(58.8)$ & 0.715 \\
\hline A & 72 & $(25.8)$ & $16(23.5)$ & \\
\hline B & 31 & $(11.1)$ & $11 \quad(16.2)$ & \\
\hline $\mathrm{AB}$ & 5 & (1.8) & $1 \quad(1.5)$ & \\
\hline Rhesus factor & & & & \\
\hline Positive & 259 & $(92.8)$ & $61 \quad(89.7)$ & 0.388 \\
\hline Negative & 20 & (7.2) & $7 \quad(10.3)$ & \\
\hline $\begin{array}{l}{ }^{*} \text { t-test was use } \\
\text { diseases, blo } \\
\text { ketonuria, glyc } \\
\text { cardiac diseases, } \\
\text { and hep }\end{array}$ & $\begin{array}{l}\text { globin, Pe } \\
\text { on, allergy } \\
\text { d groups. } \\
\text { al diseases } \\
\text { ace antige }\end{array}$ & $\begin{array}{l}\text { arson's Chi- } \\
\text { y, consangui } \\
\text { Fisher Exa } \\
\text { renal disea } \\
\text { n. GDM: g }\end{array}$ & $\begin{array}{l}\text { uared test was us } \\
\text { y, rhesus factor, } \\
\text { est was used for } \\
\text { infection, smo } \\
\text { ational diabetes }\end{array}$ & $\begin{array}{l}\text { r thyroid } \\
\text { inuria, } \\
\text { rtension, } \\
\text { antibodies } \\
\text { tus }\end{array}$ \\
\hline
\end{tabular}


estimates that 17.8 million live births to women in 2015 involved gestational diabetes, that $85.1 \%$ of all hyperglycemia cases occur during pregnancy, and that one in 7 births is affected by GDM. The IDF also indicated that one in 25 pregnancies worldwide involves GDM, including 4 million women annually presenting with GDM in India alone. ${ }^{7}$ There are published papers on the prevalence of GDM in various countries, although these studies differ in their method of screening and diagnosing GDM. The most commonly used criteria include those suggested by the World Health Organization (WHO), International Association of the Diabetes and Pregnancy Study Groups (IADPSG), and ADA, which were also used in the present study. ${ }^{8,12}$ The main differences between these criteria include the cut-off values for positive results and in the tests they use. The tests include the 1-h GCT, 2-h OGTT, 3-h OGTT, fasting blood glucose, and random blood glucose tests. ${ }^{1}$ In our research, we want to compare the prevalence of GDM in developed, developing, and some Gulf countries, while focusing on the criteria used in the studies. In addition, we want to compare the risk factors recognized in our paper with those in other studies.

The prevalence in developed countries was $5.7 \%$ in Australia, 10-11\% in Finland, 3.7\% in Germany, 4.3\% Greenland, and $12.4 \%$ in Ireland using the IADPSG criteria. The prevalence in Scotland was $1.9 \%$, Sweden was $2.2 \%$, and USA was found to be $<1.5 \%$ or up to $8.0 \%{ }^{13-20}$ In Hungary, the prevalence was measured using WHO criteria was $8.7 \%$ and the IADPSG criteria was $16.6 \% .^{21}$

In contrast, the prevalence of GDM in developing countries such Bangladesh were 9.7\% (WHO criteria) and $12.9 \%$ (ADA criteria); China were $8.1 \%$ (WHO criteria) and $9.3 \%$ (IADPSG criteria); India were $10.5 \%$ (WHO criteria) and $15.7 \%$ (IADPSG criteria); Iran was $41.9 \%$ (IADPSG criteria); lastly, Rafsanjan (a city in Iran) were 9.3\% (WHO criteria), 15.2\% (ADA criteria), and $31 \%$ (IADPSG criteria). It appears that the use of the IADPSG criteria leads to a higher prevalence of GDM, and the study conducted in Rafsanjan is a pertinent example. ${ }^{22-26}$

Finally, among Gulf countries, a population-based study covering the period from January 2001 to December 2002 was conducted in Bahrain using a 2-step protocol (50 g GCT and $75 \mathrm{~g}$ OGTT), and reported the prevalence of GDM as $13.5 \%(n=10495)$; thus, that study considered people from Bahrain as a high-risk ethnic group for GDM. Another retrospective study was conducted in Oman using a 2-step protocol and covered the period from January 2009 and December
2010 , and reported that $10 \%$ of 5811 screened women had GDM. ${ }^{27,28}$

The prevalence of $19.6 \%$ based on the ADA criteria in the present study may be considered high, and can be explained by dietary habits, and by the reasoning that the metabolism is in overdrive during pregnancy, which can exacerbate glucose intolerance and lead to GDM. ${ }^{1}$ Developed countries have a lower prevalence of GDM compared with developing countries, even judged using IADPSG criteria, which have been found to inflate the prevalence. This may be attributed to the higher level of education, better healthcare systems, and available access to health care facilities in developed countries.

Regarding the risk factors, we found that advanced maternal age and higher BMI are significantly associated with GDM. A study conducted among Asian subgroups (Indian, Chinese, Filipino, Japanese, Korean, and Vietnamese), Hispanics and Africans in 2015 showed a strong relationship between overweight/obesity, advanced maternal age, family history of type 2 diabetes, foreign-born status and an increased risk of GDM. Ethnicity play a role in the contribution of each risk factor, as they vary in their prevalence among different populations. ${ }^{4}$ Moreover, early pregnancy vitamin D status, particularly the concentration of $25[\mathrm{OH}] \mathrm{D} 3$, is inversely associated with GDM risk, and women with blood groups other than $\mathrm{AB}$ were reportedly more likely to develop GDM compared with those with blood group $\mathrm{AB}$ in Tianjin, China. ${ }^{29-31}$ Furthermore, maternal age and BMI exhibited interactions with race in terms of their relationship with GDM prevalence. Both factors are important in the development of GDM, particularly among African and South Asian women. ${ }^{31}$

Gestational diabetes mellitus mothers are at high risk of pregnancy complications. Studies have found that GDM increases the risk of developing diabetes to more than 7 times, and that approximately $50 \%$ of GDM pregnant women will develop diabetes. ${ }^{6}$ Another study conducted in the United States found that adolescent pregnancies with GDM had a higher degree of preterm delivery, mild preeclampsia, severe preeclampsia, eclampsia, induction of labor, intrauterine fetal demise, and infant death, compared with adult pregnancies with GDM. In contrast, the rates of cesarean section were higher among the adult pregnancies with GDM. ${ }^{5}$

Study limitations. We recommend routine screening for GDM and awareness leaflets and campaigns regarding the importance of adherence to antenatal follow-up appointments. However, the present study had some limitations. One of them is the availability of multiple diagnostic criteria for GDM. Another limitation we had is that we did not include patients 
who are older than 45 years due to lower numbers of pregnancy in this age group. Moreover, our study was conducted in three NGHA health care primary centers in Jeddah and included only NGHA eligible patients (National Guard soldiers, employees and their dependents) while outside patients were not involved. Additionally, some patients started their antenatal visits in NGHA clinics but continued somewhere else, which led to incomplete antenatal sheet in their electronic files. All in all, our results seem to agree with the global trend of the increasing prevalence of GDM.

In conclusion, the prevalence of GDM in Saudi Arabia is high compared to other countries. Advanced maternal age and higher BMI were associated with increased prevalence of GDM. Early prevention and management of GDM are vital to minimize the risks to both the mother and fetus.

Acknowledgment. The authors gratefully acknowledge Dr. Mohamed Eldigire, Assistant Professor of Statistics, for providing his assistance in reviewing the statistical analysis of this study. We would also like to thank Oxford Science Editing (http://www.oxfordscience. org/) for English language editing.

\section{References}

1. Classification and diagnosis of diabetes: standards of medical care in diabetes-2019. Diabetes Care 2019; 42: S13-S28.

2. Foley C, Kalro BN. The Johns Hopkins Manual of Gynecology and Obstetrics. 3rd ed. In: Bankowski BJ, Hearne AE, Lambrou N, Fox HE, Wallach E, editors. Philadelphia (PA): Lippincott Williams \& Wilkins; 2007. p. 631.

3. Pfeifer SM, editor. National Medical Series for Independent Study. Obstetrics and Gynecology. 7th ed. Philadelphia (PA): Lippincott Williams \& Wilkins Health; 2012. p. 522.

4. Pu J, Zhao B, Wang EJ, Nimbal V, Osmundson S, Kunz L, et al. Racial/ethnic differences in gestational diabetes prevalence and contribution of common risk factors. Paediatr Perinat Epidemiol 2015; 29: 436-443.

5. Penfield CA, Pilliod RA, Esakoff TF, Valent AM, Caughey AB. Adolescent maternal age is associated with increased risk of perinatal complications in gravidas with gestational diabetes. Am J Obstet Gynecol 2016; 214: S324-S325.

6. Damm P, Houshmand-Oeregaard A, Kelstrup L, Lauenborg J, Mathiesen ER, Clausen TD. Gestational diabetes mellitus and long-term consequences for mother and offspring: a view from Denmark. Diabetologia 2016; 59: 1396-1399.

7. International Diabetes Federation. IDF Diabetes Atlas 7th Edition (2015). [Updated 2019. Cited 2019 June 24]. Available from URL: https://www.idf.org/e-library/epidemiologyresearch/diabetes-atlas/13-diabetes-atlas-seventh-edition.html

8. Metzger BE, Gabbe SG, Persson B, Buchanan TA, Catalano PA, Damm P, et al. International Association of Diabetes and Pregnancy Study Groups recommendations on the diagnosis and classification of hyperglycemia in pregnancy. Diabetes Care 2010; 33: 676-682.
9. McIntyre HD, Colagiuri S, Roglic G, Hod M. Diagnosis of GDM: a suggested consensus. Best Pract Res Clin Obstet Gynaecol 2015; 29: 194-205.

10. Hadden DR. A historical perspective on gestational diabetes. Diabetes Care 1998; 21 Suppl 2: B3-B4.

11. Carrington ER, Shuman CR, Reardon HS. Evaluation of the prediabetic state during pregnancy. Obstet Gynecol 1957; 9: 664-669.

12. World Health Organization. Diagnostic criteria and classification of hyperglycaemia first detected in pregnancy: a World Health Organization Guideline. Diabetes Res Clin Pract 2014; 103: 341-363.

13. O'Sullivan EP, Avalos G, O'Reilly M, Dennedy MC, Gaffney G, Dunne FP. Atlantic DIP: the prevalence and consequences of gestational diabetes in Ireland. Irish Medical Journal 2012; 105: 13-15.

14. Lamberg S, Raitanen J, Rissanen P, Luoto R. Prevalence and regional differences of gestational diabetes mellitus and oral glucose tolerance tests in Finland. Eur J Public Health 2012; 22: 278-280.

15. DeSisto CL, Kim SY, Sharma AJ. Prevalence estimates of gestational diabetes mellitus in the United States, Pregnancy Risk Assessment Monitoring System (PRAMS), 2007-2010. Prev Chronic Dis 2014; 11: E104.

16. Chamberlain C, Joshy G, Li H, Oats J, Eades S, Banks E. The prevalence of gestational diabetes mellitus among Aboriginal and Torres Strait Islander women in Australia: a systematic review and meta-analysis. Diabetes Metab Res Rev 2015; 31: 234-247.

17. Pedersen ML, Jacobsen JL, Jorgensen ME. Prevalence of gestational diabetes mellitus among women born in Greenland: measuring the effectiveness of the current screening procedure. Int J Circumpolar Health 2010; 69: 352-360.

18. Huy C, Loerbroks A, Hornemann A, Rohrig S, Schneider S. Prevalence, Trend and Determining Factors of Gestational Diabetes in Germany. Geburtshilfe Frauenheilkd 2012; 72: 311-315.

19. Collier A, Abraham EC, Armstrong J, Godwin J, Monteath $\mathrm{K}$, Lindsay R. Reported prevalence of gestational diabetes in Scotland: The relationship with obesity, age, socioeconomic status, smoking and macrosomia, and how many are we missing? J Diabetes Investig 2017; 8: 161-167.

20. Ignell C, Claesson R, Anderberg E, Berntorp K. Trends in the prevalence of gestational diabetes mellitus in southern Sweden, 2003-2012. Acta Obstet Gynecol Scand 2014; 93: 420-424.

21. Kun A, Tornoczky J, Tabak AG. The prevalence and predictors of gestational diabetes mellitus in Hungary. Horm Metab Res 2011; 43: 788-793.

22. Gopalakrishnan V, Singh R, Pradeep Y, Kapoor D, Rani AK, Pradhan S, et al. Evaluation of the prevalence of gestational diabetes mellitus in North Indians using the International Association of Diabetes and Pregnancy Study groups (IADPSG) criteria. J Postgrad Med 2015; 61: 155-158.

23. Jafari-Shobeiri M, Ghojazadeh M, Azami-Aghdash S, NaghaviBehzad M, Piri R, Pourali-Akbar Y, et al. Prevalence and risk factors of gestational diabetes in Iran: a systematic review and Meta-Analysis. Iran J Public Health 2015; 44: 1036-1044.

24. Leng J, Shao P, Zhang C, Tian H, Zhang F, Zhang S, et al. Prevalence of gestational diabetes mellitus and its risk factors in Chinese pregnant women: a prospective population-based study in Tianjin, China. PloS One 2015; 10: e0121029. 
25. Moradi S, Shafieepour MR, Mortazavi M, Pishgar F. Prevalence of gestational diabetes mellitus in Rafsanjan: a comparison of different criteria. Med J Islam Repub Iran 2015; 29: 209.

26. Jesmin S, Akter S, Akashi H, Al-Mamun A, Rahman MA, Islam $\mathrm{MM}$, et al. Screening for gestational diabetes mellitus and its prevalence in Bangladesh. Diabetes Res Clin Pract 2014; 103: 57-62.

27. Abu-Heija AT, Al-Bash M, Mathew M. Gestational and pregestational diabetes mellitus in Omani women: comparison of obstetric and perinatal outcomes. Sultan Qaboos Univ MedJ 2015; 15: e496-e500.

28. Al Mahroos S, Nagalla DS, Yousif W, Sanad H. A populationbased screening for gestational diabetes mellitus in non-diabetic women in Bahrain. Ann Saudi Med 2005; 25: 129-133.
29. Zhang C, Li Y, Wang L, Sun S, Liu G, Leng J, et al. Blood group $\mathrm{AB}$ is protective factor for gestational diabetes mellitus: a prospective population-based study in Tianjin, China. Diabetes Metab Res Rev 2015; 31: 627-637.

30. Arnold DL, Enquobahrie DA, Qiu C, Huang J, Grote N, VanderStoep A, et al. Early pregnancy maternal vitamin $\mathrm{D}$ concentrations and risk of gestational diabetes mellitus. Paediatr Perinat Epidemiol 2015; 29: 200-210.

31. Makgoba M, Savvidou MD, Steer PJ. An analysis of the interrelationship between maternal age, body mass index and racial origin in the development of gestational diabetes mellitus. BJOG 2012; 119: 276-282.acial origin in the development of gestational diabetes mellitus. BJOG 2012; 119: 276-282.

\section{Case Reports}

Case reports will only be considered for unusual topics that add something new to the literature. All Case Reports should include at least one figure. Written informed consent for publication must accompany any photograph in which the subject can be identified. Figures should be submitted with a $300 \mathrm{dpi}$ resolution when submitting electronically. The abstract should be unstructured, and the introductory section should always include the objective and reason why the author is presenting this particular case. References should be up to date, preferably not exceeding 15 . 